\title{
'SIGNPOSTING' RESEARCH STORIES IN DOCTORAL THESES: WRITING THAT KEEPS THE READER IN MIND
}

\author{
Shosh Leshem \\ Kibbutzim College of Education and Stellenbosch University \\ Eli Bitzer \\ Stellenbosch University
}

\begin{abstract}
One critical component in doctoral theses is having the readers in mind by orienting them to 'the story of the research'. The candidate might be writing for an audience familiar with the broader content, however, when original material is explained and put in context, exceptional emphasis on clarity might be needed. Readers would therefore appreciate signposts to direct them on their journey through the work.
\end{abstract}

The aim of our study is twofold: Firstly, to identify and briefly reflect on the signposts or links that make thesis texts more reader-friendly and assist the reader in understanding the text. Secondly, we selected and analysed eight completed theses in relation to three of these critical research components that play a pivotal role in creating coherence and cohesiveness in a study: conceptual frameworks, research questions and theoretical perspectives.

Our primary sources were eight completed doctoral theses in education from different universities. The analysis of the selected theses identified signposting with varied measures of success: while in some studies the signposting was most helpful, in others it seemed vague, handled clumsily or over-used. The paper should alert candidates and supervisors to ways and means of making their writing more reader-friendly and thus promote their chances of positive examiner impressions.

Keywords: doctorateness; signposting; writing strategies

\section{INTRODUCTION}

Why do readers of doctoral theses and examiners struggle to follow the research stories of doctoral candidates? Conversely, how can doctoral candidates assist their readers in making an already complex task easier, thereby positively influence the evaluation of their work?

One critical component in doctoral theses is having the readers in mind by orienting them to 'the story of the research' and by making their thinking visible so that readers can follow the 'story'. In the process of writing, readers create writers and writers create readers; in the meeting of these two lie meaning and communication (Ede \& Lunsford, 1984). The candidate is writing for an audience that is not already familiar with the content and when original material is explained and put into context, exceptional emphasis on clarity might be needed (Reese, 1996). 
The examiner is a reader like any other reader who wishes to become engaged in the thesis and thus requires guidance to navigate through it (Johnston, 1997). Readers tend to get lost quite easily because of the sheer volume of information in theses. The wise writer thus uses bridging text and signposts as conceptual links, joining factors, summaries leading on to the next section, or as flagging texts to indicate something which will be mentioned later (Rug \& Petre, 2004). Readers would therefore appreciate signposts to help them navigate the path they are taking through the work. Nevertheless, the notion of having the reader in mind is often taken for granted and is not given sufficient attention (Leshem, Bitzer \& Trafford, 2018; Booth, Colomb \& Williams, 2008) yet it creates a reciprocal relationship and a generative writer-reader relationship.

\section{THEORETICAL PERSPECTIVES}

Kamler and Thomson (2006) address the relationship between the reader and the writer and refer to developing writerly and readerly purposefully structured theses to be more readerly. This is where authors attempt to steer the reader through a linear set of moves towards a narrative closure and 'tempt(s) the reader into reading' (2006:129). Kamler and Thomson also suggest (2006:129) that it is sometimes helpful to provide structured guidance and thereby encourage doctoral researchers to consider paying close attention to matters such as sentence construction, syntax and paragraphing. They refer to signposting as headings and subheadings that are important tools to help the reader see how the thesis is organised and staged as a coherent argument (2006: 96). They point out that writing activities that help to construct an argument are central to producing reader-friendly texts.

Becker and Denicolo (2012) use the concept of signposting in their work to promote good writing structures that could be helpful to readers. They point to words and sentences as signposts that can effectively link ideas and guide readers through a piece of argumentative writing. Different words (as signposts) have different purposes. For instance, words like 'however', 'therefore', 'in conclusion' prepare the reader for something to happen - either moving a position, stating a qualification, announcing a contradiction or ending a section. Words like 'whilst', 'whereas' and 'although' might indicate a proposition that follows or a qualification or a contradiction attached to it. Useful words like 'further', 'furthermore' and others add momentum to the writing and announce deeper or more layers of argumentation. The authors caution, however, that an overuse of such terms might distort rather than promote the writing.

Signposts are also the visible structure of the thesis and argument. Some opportunities for signposting are the titles and subtitles of chapters that can help readers see the development of the argument. Sound introductions to chapters can explain their role in the overall argument while good chapter conclusions might summarise the main points, reminding readers how they fit in with the overall argument and point to what will follow in ensuing chapters (Bonnett, 2008).

In the technical sections of writing, i.e., when using tables, graphs and diagrams to report results, clarification sentences and paragraphs are necessary to link different pieces of information as portrayed. Readers should be kept in the loop by the author, indicating how different results sections hang together and make sense. Producing the results of an inquiry without properly indicating the links among the results sections (especially in the case of mixed-methods research designs) could present a significant problem for readers. 
A particularly important element of thesis signposting is how authors present their research storyline. This issue, highlighted by Toulmin (1958) provided the basis of our analysis of eight doctoral theses when we selected key signposts as our focus, namely the use of conceptual frameworks, research questions and literature.

\section{Toulmin's Model}

Toulmin emphasises the importance of argumentative language to communicate to examiners/readers the author's knowledge claims. He suggests that readers look for how the relevant research evidence support knowledge claims, whether data are worthy of mediating the links between claims and data, whether there are sufficient qualifiers to the claims and whether there are counter-arguments that strengthen the claims or make them more flexible and thus strengthens a coherent storyline. Toulmin also suggests that research claim(s) need to be clear and might involve opposing views or different ways of interpreting statements. In a doctoral thesis, the central knowledge claim is observed in the research questions and such questions thus need to involve precision, accuracy and clarity. Knowledge claims are mediated through conceptual understanding as embodied by conceptual frameworks while, in turn, conceptual frameworks are mainly informed by literature.

Further elaborating on Toulmin's model, Wentzel (2018:60 - 88) points to particular conditions assisting towards a sound research story. For instance, the research problem might claim that there is something about a real-life problem not currently known. The inquiry might show that this is the case but is only warranted by a systematic review of relevant literature that indeed shows a measure of inadequacy. A counterargument might respond to those who think that nothing is wrong or missing in the current research into the problem.

Building a sound research story thus logically needs linkages or connections among argumentative positions or arguments. In a good thesis, all its sections and features link into a coherent whole to contribute to an overall, logical argument (Wentzel 2018: 63 - 64). This includes how candidates can find and foreground their own voice in communicating to readers with clarity; explicate their conceptual framework and indicate how such a framework play a role in the research, how research questions are foregrounded and how relevant literature are used.

\section{Doctorateness and Examiners' Impressions}

Considering examiners as the pivotal readers of a thesis, it should be a compelling story 'which others would want to read' (Winter, Griffiths \& Green, 2000:36). Examiners attribute much importance to first impressions. It is therefore advisable to leave them with favourable memories, especially of how the thesis was presented in a synergetic way (Trafford \& Leshem: 160). Synergy, according to Trafford and Leshem (2011), is one of the most critical signposts of doctorateness and when apparent in the thesis, examiners and other readers will recognise it and appreciate the thesis to be a conceptually coherent and well-presented piece of work. The language of doctorateness thus requires more than a simple summation of the components that comprise the research process to appreciate what it involves. If there is dependency between these separate components, the nature of their interdependencies will determine their collective and overall effectiveness to support the researcher's storyline (Trafford and Leshem 2008:36). 


\section{The Linking Function of Conceptual Frameworks (CF)}

The notion of the conceptual framework is presented differently by different authors. However, most authors use the term to describe a set of relationships within the research process. For example, Miles and Huberman (1984) accommodate the purpose (boundaries) with the flexibility (evolution) and coherence of the research (plan/analysis/conclusion) which all stem from conceptual frameworks. Weaver-Hart (1988: 11) views a conceptual framework as: 'A structure for organising and supporting ideas' while Berger and Patchener (1988) as well as Ravitch and Riggan (2012) propose that a conceptual framework guides the entire research process.

Both these sources advocate a pluralist and cyclical role for conceptual frameworks indicating traceable connections between theoretical perspectives, research strategy and design, fieldwork, and the conceptual significance of the evidence by shaping the conceptual conclusions and closing the research. Thus, the conceptual framework serves as a bridge between paradigms which explain the research issue and the practice of investigating that issue (Leshem \& Trafford, 2008). Ravitch and Riggan (2012) support this position, claiming that the conceptual framework guides how researchers think about collecting, analysing, describing and interpreting data and accordingly serves as a core driving component of the empirical research cycle.

\section{The Linking Function of Research Questions (RQ)}

Research questions are key structural devices in doctoral research and feature prominently in a thesis. It is common for them to appear in different thesis sections as they represent the link between the intention and the outcome (Alvesson \& Sandberg, 2013). This is well portrayed in the magic circle model (Trafford \& Leshem, 2008: 170), showing how research questions lead into the theoretical perspectives gleaned from the literature. In turn, the theoretical perspectives enable doctoral candidates to devise a conceptual framework that is central to the design of the research. The iterative relationship between fieldwork and research design acknowledges how these features influence each other through the duration of the research. Likewise, the data collected enable the generation of conclusions claiming a contribution to knowledge that relates to the research question(s) and the identified research gap, thereby closing the circle and connecting beginnings to endings.

\section{The Linking Function of the Literature Review (LR)}

The literature review is an essential part of the doctoral research process and is integral to the success of academic research. It combines theories on the topic with methodologies by making the gap of the research explicit, delimits the boundaries of the research with theoretically justified reasons, represents the conceptual foundations to design of the research and gives conceptual focus to the conclusions (Grant, 2010; Xiao \& Watson, 2019). Literature therefore represents the conceptual thread that runs through a doctoral thesis, making connections between ideas. This results in achieving cohesion in the arguments and conceptual depth for the thesis.

\section{OUR STUDY}

This study aimed to identify the signposts or links in selected thesis texts that make them more reader-friendly and assist the reader in understanding the research story. Therefore, we 
posed the following question: How do candidates use signposts in doctoral theses to make conceptual interdependencies visible to their readers?

We chose to focus on evidence related to three critical research components, briefly explained above, that play a central role in creating coherence and cohesiveness in a study: conceptual frameworks, research questions and theoretical perspectives. We looked at how candidates have signposted their writing journeys by using these three components as conceptual linkages between and within their research.

Our primary sources were eight doctoral theses in education, completed between 2015 and 2019 and randomly selected from three different universities in two countries (Israel and South Africa). The theses were downloaded from the respective library repositories and consequently, as investigators, we did not need the authors' consent. Each investigator did an in-depth analysis of text linkages in four theses.

The initial examination of the linking features involved a search of key phrases, including conceptual framework, theoretical framework, theory, research questions and argument to provide a rough impression of their reoccurrence in the text. We then looked more closely at the context where they appeared and their linking function, if at all. The data and the interpretations were organised in a table presenting the linking feature evidenced from the theses and our own comments. The tables were cross-read and discussed by the investigators to arrive at a common final map of the linking features and their functions in the eight theses.

\section{FINDINGS}

In this section, we provide representational examples of the CF, RQ and LR and their linking functions as they appear in the eight theses. We interpreted the findings and discussed them in light of the relevant literature on linking functions. Table 1 provides an idea of how we classified and grouped the raw data for one thesis. We followed the same procedure for the remaining seven theses.

Table 1: Features that point to links that make a thesis more readable - Thesis 1 (T1)

\begin{tabular}{|c|c|c|}
\hline Link feature & $\begin{array}{l}\text { Evidence found/not found in } \\
\text { thesis }\end{array}$ & Comments \\
\hline $\begin{array}{l}\text { The research } \\
\text { question(s) - } \\
\text { clarity, how } \\
\text { many times } \\
\text { referred to and } \\
\text { for what } \\
\text { purpose? }\end{array}$ & $\begin{array}{l}\text { The overall RQ, with four sub- } \\
\text { questions, appear three times in the } \\
\text { thesis. Once in the introductory } \\
\text { chapter and twice in the final } \\
\text { chapter. The first time it follows on } \\
\text { introducing the problem (a lack of } \\
\text { transformative learning in } \\
\text { educational leadership) and in the } \\
\text { last chapter, it serves to (a) remind } \\
\text { the reader what the questions were } \\
\text { and (b) highlight the research } \\
\text { answers to the formulated RQs. }\end{array}$ & $\begin{array}{l}\text { The RQ seems clear and the four } \\
\text { sub-questions tie well into the RQ. } \\
\text { The repetition of the RQ (twice) } \\
\text { seems effectively used in Chapter } 8 \\
\text { - first to remind the reader about } \\
\text { the main research concern and then } \\
\text { to link the findings to each of the } \\
\text { sub-questions to provide answers to } \\
\text { these questions. }\end{array}$ \\
\hline $\begin{array}{l}\text { The } \mathrm{CF}-\text { how } \\
\text { do different } \\
\text { sections link to } \\
\text { the CF? The }\end{array}$ & $\begin{array}{l}\text { The term conceptual framework is } \\
\text { not mentioned in the thesis. What is } \\
\text { referred to, are terms such as } \\
\text { personal developmental theory, }\end{array}$ & $\begin{array}{l}\text { The theory concept features } \\
\text { prominently in this thesis. The term } \\
\text { is sometimes even used somewhat } \\
\text { confusingly as many variations of }\end{array}$ \\
\hline
\end{tabular}




\begin{tabular}{|c|c|c|}
\hline $\begin{array}{l}\text { intro, the } \\
\text { literature, the } \\
\text { findings and } \\
\text { the } \\
\text { conclusions? }\end{array}$ & $\begin{array}{l}\text { theoretical framework, theoretical } \\
\text { underpinning, theoretical } \\
\text { perspective, theoretical } \\
\text { understanding and theoretical } \\
\text { paradigm - all used in different } \\
\text { sections of the thesis. For instance, } \\
\text { a diagram, depicting the whole } \\
\text { thesis (p. iii) provides a clear link } \\
\text { between the RQ and the three } \\
\text { foundations of the theoretical } \\
\text { perspective, namely transformative } \\
\text { learning, facilitating transformative } \\
\text { learning and leadership } \\
\text { development. The links among } \\
\text { these key concepts appear again in } \\
\text { Chapter } 2 \text { (Literature), Chapter } 6 \\
\text { (Results) and Chapter } 8 \\
\text { (Discussion of findings and } \\
\text { conclusions). }\end{array}$ & $\begin{array}{l}\text { the term theory are referred to. } \\
\text { However, what became clear is that } \\
\text { links exist among the study's key } \\
\text { concepts to the literature review, } \\
\text { the study results, discussion of the } \\
\text { findings and drawing of } \\
\text { conclusions. The identified } \\
\text { implications of the study (Chapter } \\
\text { 8) tie well into the adopted } \\
\text { theoretical frame and suggest how } \\
\text { the current theoretical } \\
\text { understanding of the problem could } \\
\text { lead to improved practices (i.e., } \\
\text { facilitating transformative learning } \\
\text { with leaders within a particular } \\
\text { educational context). }\end{array}$ \\
\hline $\begin{array}{l}\text { The literature - } \\
\text { merely } \\
\text { reported or } \\
\text { clear } \\
\text { engagement? } \\
\text { Author as } \\
\text { discussion } \\
\text { leader to direct } \\
\text { the discourse. } \\
\text { Author's voice } \\
\text { and synthesis } \\
\text { provided for } \\
\text { the reader? }\end{array}$ & $\begin{array}{l}\text { The literature review in this thesis } \\
\text { spans three chapters (2, } 3 \text { and } 4 \text { ), } \\
\text { each exploring one key concept } \\
\text { (transformative learning theory, } \\
\text { facilitating transformative learning } \\
\text { and leadership development). The } \\
\text { review is in all three instances } \\
\text { accompanied by excerpts from the } \\
\text { author's reflective diary and her } \\
\text { professional learning experiences. } \\
\text { It thus shows a clear engagement } \\
\text { with relevant literature and the } \\
\text { emergence of a strong theoretical } \\
\text { voice. For instance, in her summary } \\
\text { of Chapter 2, the author says (p. } \\
\text { 249): 'Through such integrative } \\
\text { review process, I was able to } \\
\text { develop a literature review } \\
\text { argument map. The literature } \\
\text { review argument map was helpful } \\
\text { to determine a research gap, within } \\
\text { which I could position my } \\
\text { research'. }\end{array}$ & $\begin{array}{l}\text { The literature review, spanning } \\
\text { three chapters, is quite impressive } \\
\text { and thorough. The author engages } \\
\text { deeply with the literature, her voice } \\
\text { seems visible throughout the } \\
\text { narrative and often shows links } \\
\text { between personal reflection, } \\
\text { professional experience and other } \\
\text { authors' theoretical perspectives. } \\
\text { At the end of each of the three } \\
\text { literature chapters, a synthesis } \\
\text { provides a link into the chapters } \\
\text { that follow and towards the end of } \\
\text { the thesis (Chapter 8) an overall } \\
\text { synthesis of the literature also } \\
\text { emerges as a reminder of the most } \\
\text { important theoretical points. }\end{array}$ \\
\hline $\begin{array}{l}\text { Writing } \\
\text { features: } \\
\text { Linking words } \\
\text { linking } \\
\text { sentences/ } \\
\text { phrases, links } \\
\text { among }\end{array}$ & $\begin{array}{l}\text { Ample evidence of linkages among } \\
\text { paragraphs appeared (e.g., Chapter } \\
1, \text { pp. 4-5 and elsewhere). } \\
\text { However, there was also evidence } \\
\text { of inconsistencies in the use of } \\
\text { terminology (e.g., in the same } \\
\text { paragraph one event was referred to }\end{array}$ & $\begin{array}{l}\text { In terms of writing, several links in } \\
\text { the thesis seem clear. What is a } \\
\text { prominent feature is the ability of } \\
\text { the author to structure and explicate } \\
\text { her thought processes regarding } \\
\text { different parts of the thesis visually } \\
\text { through tables and figures (also }\end{array}$ \\
\hline
\end{tabular}




\begin{tabular}{|c|c|c|}
\hline $\begin{array}{l}\text { subsections, } \\
\text { sections and } \\
\text { chapters? }\end{array}$ & $\begin{array}{l}\text { respectively as a conference, a } \\
\text { congress and a convention). Links } \\
\text { among sections of the thesis are } \\
\text { quite evident (e.g., 'In this section, } \\
\text { the background and institutional } \\
\text { context of the particular sector have } \\
\text { been explained. The next section } \\
\text { will provide the legislative } \\
\text { framework, from which the } \\
\text { relevant sector derive their } \\
\text { legislative mandate for their } \\
\text { operations' (as on p.5 and } \\
\text { elsewhere). Relevant tables and } \\
\text { figures, outlining the thought } \\
\text { process of the author's inquiry are } \\
\text { presented throughout chapters. For } \\
\text { example, Table } 1.1 \text { (p. } 24 \text { ) presents } \\
\text { an argumentative outline of the } \\
\text { study, indicating the flow of the } \\
\text { action that the research process } \\
\text { followed. Similar tables were } \\
\text { presented elsewhere to clarify } \\
\text { thinking processes (e.g., pp. } 31,34 \text {, } \\
39,44 \text { and } 68 \text { ). The author colour- } \\
\text { coded all diagrams to make reading } \\
\text { easier. }\end{array}$ & $\begin{array}{l}\text { using colour-coding). This helps to } \\
\text { appreciate the overall links among } \\
\text { the different sections and chapters } \\
\text { of the thesis as well as spotting the } \\
\text { links that point to meaning and } \\
\text { logic among key concepts. }\end{array}$ \\
\hline $\begin{array}{l}\text { Argumentative } \\
\text { features and } \\
\text { features of } \\
\text { logic? Claims, } \\
\text { data, warrants, } \\
\text { questioning } \\
\text { and rebuttals? }\end{array}$ & $\begin{array}{l}\text { The term argument' appears at least } \\
65 \text { times in the thesis text. In most } \\
\text { cases, it describes the logic of a } \\
\text { particular view or model [such as in } \\
\text { the following excerpt: 'I regard } \\
\text { Chapter } 1 \text { as the engine that drives } \\
\text { the rest of the document, which } \\
\text { therefore needs to provide a } \\
\text { complete empirical argument, } \\
\text { describing the background of the } \\
\text { problem, the statement of the } \\
\text { problem and purpose of the study' } \\
\text { (p. ii)]. The author's links into } \\
\text { argumentation are more clearly } \\
\text { observed in her putting forward and } \\
\text { justifying claims. For example, (p. } \\
9 \text { ): 'My argument presented here is } \\
\text { that there is a need for leadership } \\
\text { development in the sector. My } \\
\text { reason for holding this view is that } \\
\text { colleges were criticised in the past } \\
\text { for not producing sufficient quality } \\
\text { in the management and delivery of }\end{array}$ & $\begin{array}{l}\text { The author uses the term argument } \\
\text { or my argument throughout the } \\
\text { thesis as a link towards clarifying } \\
\text { her argumentative process for the } \\
\text { reader. The steps or characteristics } \\
\text { of the Toulmin model are not } \\
\text { always followed closely but the } \\
\text { idea of argumentation stands out } \\
\text { clearly, allowing for a scholarly } \\
\text { impression of the work. Authors of } \\
\text { theses do not often appear to be } \\
\text { making their arguments clear and } \\
\text { engage in argumentative writing, } \\
\text { but in this instance the opposite } \\
\text { was true. }\end{array}$ \\
\hline
\end{tabular}




\begin{tabular}{|c|c|c|}
\hline & $\begin{array}{l}\text { teaching and learning. The above- } \\
\text { mentioned statement is reflected in } \\
\text { the weak output of graduates and } \\
\text { limited access of students to } \\
\text { workplace learning opportunities } \\
\text { (HRDC, Annual Report } \\
\text { 2015/2016)'. }\end{array}$ & \\
\hline $\begin{array}{l}\text { Other } \\
\text { (commendable) } \\
\text { features? }\end{array}$ & $\begin{array}{l}\text { Throughout the thesis, tables and } \\
\text { diagrams are used to introduce, } \\
\text { highlight or synthesise particular } \\
\text { sections or chapters. }\end{array}$ & $\begin{array}{l}\text { While some scholarly readers } \\
\text { might find too many tables and } \\
\text { diagrams interfering with the flow } \\
\text { of text, the view was that in the } \\
\text { case of this thesis it serves as a } \\
\text { helpful feature to link thought } \\
\text { structures and processes. }\end{array}$ \\
\hline
\end{tabular}

\section{The conceptual framework (CF)}

The CF as a term is not always literally mentioned in theses but the theory concept can still feature heavily through different representations such as a theoretical framework, theoretical underpinnings, theoretical perspectives, theoretical understandings and theoretical paradigm.

In one thesis, for example, the different terms are used in different sections of the thesis as a diagram, depicting the whole thesis, thereby providing a clear link between the RQs and the foundations of the theoretical perspective. The links among the key concepts extend into the literature review, study results, discussion of the findings and the drawing of conclusions. The identified implications of the study tie well into the adopted theoretical frame and suggest how the current theoretical understanding of the problem could lead to improved practices.

However, the variations of theory as used might sometimes be confusing to the reader. For instance, in Thesis 1 terms such as personal developmental theory, theoretical framework, theoretical underpinnings, theoretical perspective, theoretical understanding and theoretical paradigm might all point to clearer conceptualisation, but this could have been better communicated under a single concept such as conceptual framework.

Thesis 2 explores an array of key concepts and the relevant chapter provides a summary of what was found in the literature but no CF (or theoretical framework - TF) is mentioned as it proceeds directly to the next chapter to discuss the analytical tool for the cases studied. Thus, Thesis 2 provides the key concepts but no clear link to one another and how they link to the analytical tool which is described at length.

In Thesis 3, the author mentions the conceptual framework at the end of the theoretical perspectives chapter as a summary, indicating that the concepts discussed in the chapter shaped the CF and promoted the methodology and the discussion. This is also mentioned in the concluding chapter, indicating its role as 'conceptualizing the findings and conclusions'. However, there was no clear and thorough explanation of what the CF really entails.

The term $\mathrm{CF}$ is quite prominent in Thesis 4 and appears numerous times. A separate chapter is devoted to this aspect towards the end of the literature review and outlines the different characteristics of a $\mathrm{CF}$, providing the relevant sources. It also explains how the $\mathrm{CF}$ emerged 
from the LR and provides different purposes of the $\mathrm{CF}$, namely that it enhances the understanding and analysis of the empirical data, establishes a context for interpreting the findings of the investigation, and enhances the understanding and analysis of the empirical data. While the signposting might guide the reader through the argument of the thesis, its elaboration in every chapter achieves the opposite effect of redundancy and laborious reading.

In Thesis 5, the author indicates in the introduction that understanding the concepts discussed in the literature review informed the generation of a conceptual framework. In this thesis, the contribution was the generation of a $\mathrm{CF}$ for understanding a particular concept and its related phenomena. This was achieved through a review of the relevant scholarly literature. It was mentioned again in the discussion chapter reminding the reader of the purpose of the thesis and then in the conclusions and the contribution indicating how it evolved from the literature. The remaining three theses followed the pattern represented in Thesis 5.

\section{Research Questions (RQ)}

In all the theses that we reviewed, the RQs appear in the thesis at least three times as reminders of the research's aims. They are usually mentioned in the introduction, in the findings or the discussion and then in the last chapter to remind the reader what the main research concerns were and to highlight the research answers to link the findings to each of the questions. There are also cases where the RQs are all stated in the first chapter but the reader is reminded of them again only in the very last chapter.

In one example, the RQs appear in each chapter of the thesis. The RQs first appear in the introduction in a section titled 'statement of purpose and research questions'. The second time, they are mentioned at the end of the LR explaining how they emanated from the literature. They are mentioned again in the methodology to explain how the paradigms chosen for the research are related to the RQs and the rationale for the methods chosen. In this chapter, the RQs are mentioned numerous times in reference to every decision made in the research design. They are referred to in the findings chapter to show how the findings of each approach related to the respective RQs. They are also referred to in the discussion and then in the conclusions (in full) as a reminder of what the research set out to investigate. Although one appreciates the repetition of RQs as a reminder of exactly what the study was about, it can become burdensome to read them repeatedly in almost all of the chapters.

\section{Literature Review (LR)}

In the literature sections of the selected theses, we looked at engagement, the author as discussion leader to direct the discourse, the author's voice and the synthesis provided for the reader.

The LR in Thesis 1 spans three chapters and is quite thorough. The author engages deeply with the literature, their voice seems visible throughout and in many instances, the narrative shows links between personal reflection, professional experience and other authors' theoretical perspectives. At the end of each of the three literature chapters, a synthesis provides a link into the chapters that follow and towards the end of the thesis (in this case Chapter 8) an overall synthesis of the literature also emerges as a reminder of the most important theoretical points. 
In another example, the LR involves a broad range of mainly primary sources, however, a synthesis at the end of the LR chapter as well as the links between this chapter and the following one are missing, indicating a lack of integration. The scholarly voice of the author does not seem to appear frequently and thus provides no links for readers in terms of letting referenced authors 'talk to one another' or providing counterviews.

In Thesis 4, the literature chapter provides an expansive, but compact review of the two key concepts featured in the main research question. The chapter then continues by exploring these two concepts from different angles and at some depth. What failed to emerge, however, was the author's own scholarly voice through integration, synthesis and summary of the theoretical concepts at crucial points. In this case, the literature chapter provided evidence of a wide range of consulted literature but the discussion lacks coherence and so largely remains at the level of description. The links pointing to an authoritative scholarly voice remain elusive.

As opposed to this example, Thesis 6 demonstrates how the author is largely in control of the debate by, for example, presenting the reader with a conceptual map in the form of a diagram with brief explanations emanating from the previous sections of literature exploration. This thesis provides ample evidence of the author being able to engage with literature at the doctoral level. Her scholarly voice rings clear and she seems in charge of the discussion, presenting different and often opposing views regarding key concepts.

In Thesis 7, the author is very much aware of the reader and walks them through every phase of the journey. In the LR chapter, the author starts with a short preview of what the section contains. Then the author describes how she compiled the sources and what considerations she had to make in choosing them. She describes the deliberations of deciding on the terms used and at the end of the chapter, she provides a summary and indicates the link between the concepts described in the LR and the conceptual framework which guides the next chapters. There are reoccurrences of the LR In the explanation of the methods of investigation where there is mention of how the LR and previous research on the topic helped in developing the interview questions or the questionnaires. Then the preview of the discussion section explains how the findings are interpreted through the lens of the theoretical perspectives. In the concluding chapter, the author returns to the $\mathrm{CF}$ and the theories under the title 'conceptualizing the findings'. In this thesis, the linkages within and between sections are quite evident but somewhat overdone as the text becomes repetitious.

\section{The Storyline}

With Toulmin's (1958) model in mind and spanning findings on the three key features as outlined, we also tried to identify how the author in each case represents the storyline of the thesis. We identified instances where the author challenged their own arguments and observations or afforded knowledge claims and logically defended them. Such evidence provides clear links to the ability of the author to communicate the research. In some theses, the authors use the term my argument throughout the thesis as a link to indicate their train of thought to the reader. The steps or characteristics of the Toulmin model were are not always followed closely but the idea of weaving arguments together often surfaced, allowing for a scholarly impression of the work. However, in some of the theses, the storyline became blurred. This was especially true where signposting in literature reviews was absent. For instance, the they say characteristic (what other authors say) was obvious, but not the I say 
feature - which perhaps indicates some candidates' limited ability to make sense of the different voices that contribute to the study's key debate.

\section{DISCUSSION}

The present study explored some answers to the question of how doctoral candidates use signposts in completed doctoral theses to make conceptual interdependencies visible to their readers. What emerged from an analysis of key communicative aspects in eight sample theses is discussed next.

\section{Conceptual Frameworks (CFs)}

The importance of synergy, coherence and links within doctoral studies have been emphasised (Trafford and Leshem 2008) and the value of sound conceptual frameworks (CFs) seems crucial at the doctoral level (Leshem and Trafford, 2007; Ratvich and Riggan, 2012). Our study revealed at least five signposts related to CFs across the eight theses:

The research story becomes clearer if

- $\quad$ key concepts are presented and discussed as reader signposts and the links among such concepts are clear;

- relevant key terms are used as linkages, including terms such as theoretical framework, theoretical underpinnings, theoretical perspectives, theoretical understandings and theoretical paradigm;

- the CF itself serves as a signpost that features prominently in different sections of a thesis and

- the CF is not over-used and elaborated on as too much elaboration of the CF in each chapter achieves the opposite effect, namely of redundancy and laborious reading.

Both these relatively positive and negative signposting features correspond with the extensive work of Ravitch and Riggan (2012) who have described the CF as both the 'guide' and 'ballast' (2012:5) of a research project. Considering the CF as key in almost all parts of a doctoral study, they refer to it as an organising force that informs both a study's theoretical and empirical parts and also assists in establishing its worth. Marshall and Rossman (2006) even refer to the CF as part of a study's argumentative strength while Maxwell (2005) considers the $\mathrm{CF}$ as justifying the research both substantively and methodologically. From a reader's perspective, one might conclude that in the reviewed theses, signposting CFs was mainly helpful in reading the different thesis sections and to spot the links among such sections. However, under-theorisation and overrepresentation of CFs are less helpful to readers and might even hinder the reading. Doctoral candidates should thus be mindful of how they develop, explain, present and use the CF throughout their studies as text signposts, thereby promoting the research story.

\section{Research Questions (RQs)}

Apart from the fact that research questions guide and direct studies, the issue of what makes research questions important at which stages of a study might be a more subjective answer since doctoral studies differ in scope and design. Overall, research questions are foundational to most research and can both guide and uncover important new insights. 
From a reader's perspective, the research story becomes clearer when

- the RQs are mentioned throughout a thesis, for example, in the introduction, the findings, discussion and then again in the final chapter to remind the reader what the main research concerns were and to highlight the research answers in linking the study's findings to each research question;

- RQs are not mentioned too frequently since such overuse is particularly bothersome when repeated in a single chapter and

- RQs are aligned within in the same study and doctoral candidates ensure that these questions appear strategically and frequently enough within their studies to remind the reader of the study's aim and focus and how such an aim and focus link to other relevant sections of the study.

As suggested by Agee (2009) and Alvesson and Sandberg (2013), research questions are of crucial importance in studies, serving as initial catalysts for the research. They provide the focus for where the research starts but often do not predict and define exactly where the research will end up. As a study unfolds and information and findings are generated, adjustments may be made as to what direction the research takes. Miin-Hwa Lim (2014) suggests that such features are often better observed in earlier drafts of theses than in the final product.

\section{Literature Reviews (LRs)}

Examiners are aware of the corpus of literature from which doctoral candidates draw their ideas and possess a sense of collectivist identity towards the literature used in theses. If a study is located in any specialised field, a particular lexicon is shared that contains technical terms with meanings most researchers in the field would agree on. This forms an immediate understanding of the writing, forming an implicit professional and scholarly link between the candidate's work and readers such as examiners (Trafford \& Leshem, 2008).

From our analysis, it emerged that the research storyline in a doctorate could be strengthened when

- engagement with relevant literature is deep, the author's 'voice' is visible and links in the narrative provide indications of personal reflection, professional experience and other authors' theoretical perspectives;

- the scholarly voice of the author is visible in presenting different and often opposing views of key concepts or issues;

- the candidate uses the study's key concepts as pointers to literature exploration, providing summaries and syntheses at appropriate intervals by indicating links between the main concepts in the LR and the CF of the study;

- links are indicated for the reader in terms of letting referenced authors 'talk to one another' or providing counterviews and

- the ensuing discussion shows coherence and elevates from the descriptive to the conceptual level.

Our findings firmly link into research on the writing of LRs that is so crucial for scholarly communication and proof of how doctoral researchers engage with reigning debates and dialogical knowledge (Kamler \& Thomson, 2006; 2008). Wisker (2015) and Wisker and Savin-Baden (2009) have inquired into ways for doctoral students and academic writers to 
overcome communication difficulties in the writing of LRs, particularly to explain their understanding of theory. Similarly, in her research, Kiley (2009) has identified moments when doctoral candidates seem to move towards greater clarity in their writing such as summarising or synthesising.

Other work on doctoral writing practices (Murray, 2005; Sword, 2009) has emphasised the development of a discursive voice of candidates in terms of enabling and demonstrating meaning-making for readers while Wisker (2015:1) points out that when doctoral candidates write LRs they need to be aware that their work builds on the works of those with authority and of precedent in the relevant field. Doctoral candidates thus need to enter the dialogue and conversation with thoroughness and confidence, showing readers that they have developed their own voice in their storyline that has 'the right to speak' (Wisker, 2015:1).

\section{The Overall Research Storyline}

The importance of strengthening the doctoral storyline through synergy among the elements of a study has been emphasised (Trafford and Leshem, 2011) while the same rings true for the need to demonstrate argumentative clarity and coherence (Wentzel, 2018). Given that the three key features (CF, RQ and LR) had been explored, some features of the research storyline emerged.

In some cases, authors foregrounded argumentative writing by using terms such as my argument, my position and my train of thought often in the thesis. In these cases, the line of argumentation appeared prominent, allowing for a scholarly impression of the work.

In other cases, however, the features of clear argumentation were not easily observable or even outright unclear as a result of weak signposting. For instance, in some LRs candidates demonstrated a limited ability to make sense of and explicate the different participating voices in the study's debate while in others, the line of argumentation was disrupted by unnecessary repetition.

Finally, it appears that a research storyline is strengthened when all three signpost elements (CF, RQ and LR) are present and well employed throughout the thesis. Since these three elements are key to any doctoral project, students may be reminded of using them to best effect to impress scholarly readers such as examiners.

\section{CONCLUSION}

Our limited explorative study indicated, with some measure of clarity, several points that relate to how doctoral candidates use (or fail to use) signposts in doctoral theses to make conceptual interdependencies visible to their readers. These pertain in particular to how the conceptual framework, research questions and the literature are used in signposting.

Nonetheless, the present study covered limited ground and we suggest that future studies might inquire deeper into the question of how doctoral candidates can make their work more reader-friendly through appropriate signposting. Such work might focus on alternative thesis elements such as the study design, methodology, the analysis and reporting of data as well as introductory and conclusions sections of studies. Other features of the research story that come to mind include the use of cross-referencing, syntheses and summaries, the closing of argumentative loops and the provision of links among sections and chapters in a thesis. 
In her book on thesis writing, Murray (2016) suggests that doctoral candidates are constantly looking for different kinds of advice and help and that many, if not most of their concerns relate to academic literacy and writing. It might be important for advisors to alert doctoral candidates to ways and means of making their writing more readerly and so doing, promote their chances of positive impressions.

\section{REFERENCES}

AGEE, J. 2009. Developing qualitative research questions: a reflective process. International Journal of Qualitative Studies in Education, 22(4).

ALVESSON, M. \& SANDBERG, J. 2013. Constructing research questions. London: Sage.

BECKER, L \& DENICOLO, P. 2012. Publishing journal articles. London: Sage.

BERGER, R. M. \& PATCHENER, M. A. 1988. Implementing the research plan. London: Sage.

LESHEM, S., BITZER E M \& TRAFFORD, V. 2018. Writing the introduction chapter of PhD theses: Comparative international perspectives. In Bitzer EM, Frick, BL, FourieMalherbe M \& Phyältö K (eds): Spaces, journeys and new horizons for postgraduate supervision. Stellenbosch: African Sun Media. 163-176.

BONNET, A. 2008. How to argue. New York: Pearson/Prentice Hall. $2^{\text {nd }}$ Edition.

BOOTH, W. C., COLOMB, G. \& WILLIAMS, J. M. 2008. The craft of research. Chicago: The University of Chicago Press. $3^{\text {rd }}$ Edition.

EDE, L. \& LUNSFORD, A. 1984. Audience Addressed/Audience Invoked: The Role of Audience in Composition Theory and Pedagogy. College Composition and Communication, Vol. 35(2):155-171.

JOHNSTON, S. (1997) Examining the examiners: An analysis of examiners' reports on doctoral theses. Studies in Higher Education, 22(3): 333-347.

KAMLER, B. \& THOMSON, P. 2006. Helping doctoral students write: Pedagogies for doctoral supervision. London: Routledge.

KAMLER, B \& THOMSON, P. 2008. The failure of dissertation advice books: Toward alternative pedagogies for doctoral writing. Educational Researcher, 37: 507-514.

KILEY, M. 2009. Identifying threshold concepts and proposing strategies to support doctoral candidates. Innovations in Education and Teaching International, 46: 293 - 304.

LESHEM, S. \& TRAFFORD, V. N. 2007. Overlooking the conceptual framework. Innovations in Education and Teaching International, 44 (1): 93-105.

MARSHALL, C \& ROSSMAN, GB. 2006. Designing qualitative research. Thousand Oaks, CA: Sage. $4^{\text {th }}$ Edition.

MAXWELL, JA. 2005. Qualitative research design: An interactive approach. Thousand Oaks, CA: Sage. $2^{\text {nd }}$ Edition.

MIIN-HWA LIM, J. 2014. Formulating research questions in experimental doctoral dissertations on Applied Linguistics. English for Specific Purposes, 35: 66-88.

MILES, M. B. \& HUBERMAN, A. M. 1984. Qualitative data analysis: a sourcebook of new methods. London: Sage.

MURRAY, R. 2005. Writing for academic journals. Maidenhead: Open University Press.

MURAY, R. 2016. How to write a thesis. Buckingham: Open University Press. $4^{\text {th }}$ Edition.

RAVITZ, SM \& RIGGAN, M. 2012. Reason \& Rigor. How conceptual frameworks guide research. Los Angeles: Sage.

REESE, A. 1996. Misfits, misprints, mistakes. Times Higher Education Supplement, 17: iv-v.

RUG, G. \& PETRE, M. 2004. The unwritten rules of PhD research. Maidenhead: Open University Press. 
SWORD, H. 2009. Writing higher education differently: A manifesto on style. Studies in Higher Education, 34: 319-336.

TOULMIN S. 1958. Uses of argument. Cambridge: Cambridge University Press.

TRAFFORD, V.N \& LESHEM, S. 2008. Stepping stones to achieving your doctorate. Buckingham: Open University Press (OUP) and McGraw-Hill Education.

TRAFFORD, V.N \& LESHEM, S. 2011. Stepping stones to achieving your doctorate. Buckingham: Open University Press (OUP) and McGraw-Hill Education. $2^{\text {nd }}$ Imprint.

WEAVER-HART, A. 1988. Framing an innocent concept and getting away with it. UCEA Review, 24(2):11-12.

WISKER, G. 2015. Developing doctoral authors: engaging with theoretical perspectives through the literature review. Innovations in Education and Teaching International, 52: $64-74$.

WENTZEL A. 2018. A guide to argumentative research writing and thinking. London: Routledge.

WINTER, R., GRIFFITHS, M. \& GREEN K. 2000. The 'academic' qualities of practice: what are the criteria for a practice-based PhD? Studies in Higher Education, 25 (1): 2537.

WISKER, G. \& SAVIN-BADEN, M. 2009. Priceless conceptual thresholds: Beyond the 'stuck place' in writing. London Review of Education, 7: 235-247.

XIAO, Y. \& WATSON, M. 2019. Guidance on conducting a systematic literature review. Journal of Planning Education and Research, 39(1): 93 -112.

\section{BIOGRAPHICAL NOTE}

Shosh Leshem is a professor in education at Kibbutzim College of Education in Israel and Middlebury College, Vermont, USA. She is also a research associate at Stellenbosch University. Her fields of research are doctoral education, supervision, teacher education and second language acquisition.

Eli Bitzer is emeritus professor in higher education studies at the Centre for Higher and Adult Education, Stellenbosch University, South Africa. He publishes in the field of postgraduate supervision and doctoral education and promotes senior degree studies. 